Research Article

\title{
A Study to Assess the Health Impact of Sutlej Floods in District Ludhiana
}

\author{
Dhruvendra Lal', Kavisha Kapoor Lal ${ }^{2}$
}

${ }^{1}$ Assistant Professor, Department of Community Medicine, Christian Medical College, Ludhiana, Punjab, India.

${ }^{2}$ Assistant Professor, Department of Periodontics, Christian Dental College, Ludhiana, Punjab, India.

DOI: https://doi.org/10.24321/2455.7048.202111

\section{I $\quad \mathbf{N} \quad \mathbf{F} \quad \mathbf{O}$}

\section{Corresponding Author:}

Dhruvendra Lal, Department of Community Medicine, Christian Medical College, Ludhiana, Punjab, India.

E-mail Id:

drdhruvlal@gmail.com

Orcid Id:

https://orcid.org/0000-0001-6973-9311

How to cite this article:

Lal D, Lal KK. A Study to Assess the Health Impact of Sutlej Floods in District Ludhiana. Epidem Int. 2021;6(3):34-37.

Date of Submission: 2021-09-07

Date of Acceptance: 2021-09-20

\section{$\begin{array}{llllllll}\mathbf{A} & \mathbf{B} & \mathbf{S} & \mathbf{T} & \mathbf{R} & \mathbf{A} & \mathbf{C} & \mathbf{T}\end{array}$}

Introduction: Disasters are never confined to any particular area, they can occur anywhere and at any time. Data collected since 1969 show a drastic increase in the number of people affected by them. More than 300 villages all over Punjab were affected by the flood in the Sutlej river in September 2019.

Objective: To assess the health impact after floods in District Ludhiana.

Method: This is a cross-sectional project which was initiated by CMC \& $\mathrm{H}$ with the help of Civil Surgeon, Ludhiana to cater to the flood-affected victims along the banks of river Sutlej covering a population of 4243 which included 10 villages. The whole population living along the river was screened and health services with preventive and curative measures, including health education were provided to the victims from 23rd August to 3rd September 2019. Cases were divided as per the post-emergency syndromic disease surveillance format of WHO.

Results: A total of 4243 people were covered over a period of 12 days. It was found that almost $26 \%$ of the victims were suffering from skin diseases post-flood followed by fever (20\%). More than 2000 chlorine tablets were also distributed.

Conclusion: $33.5 \%$ of the population was impacted. It is recommended that the focus should be on disaster preparedness. Under 5 children were most commonly affected by fever and skin infections. Special signals like fog horns should be used and people should be made aware of such signals.

Keywords: Disaster, Floods, Sutlej, Morbidity, Health Impact

\section{Introduction}

Disaster is defined as "any occurrence that causes damage, ecological disruption, loss of human life or deterioration of health and health services on a scale sufficient to warrant an extraordinary response from outside the affected community or area". Disasters are not confined to any particular area or country, but can occur at any place and at any time. Data gathered in the past have shown a drastic increase in the population affected by disasters since $1969 .{ }^{1}$

It has often been observed that mortality is high in floods when there is a sudden natural disaster like flash floods (Kedarnath) or collapse of dams. Flooding is often related to an enhanced danger of many communicable and waterborne infections. The risk of these infections remains low if 
population displacement does not occur significantly and/ or there is less contamination of water sources like ponds. The risk of an increase in water-borne diseases comes up during disasters like floods since such diseases may be contracted through direct contact with polluted waters. There may be other infections such as dermatitis, wound infections, eye flu, and ear, nose and throat infections, but these ailments do not increase to the level of an epidemic. Floods may also indirectly result in the escalation of vectorborne ailments as the number and range of vector breeding places increases. $^{2}$

The release of water from the Bhakra Dam along with heavy downpour in Punjab led to a rise in water level in rivers causing a flood in many villages during 2019. This led to large-scale harm to crops, particularly rice, and homes in low-lying areas. The total loss of livestock was estimated to be INR 91 lakh. $^{3}$

Dhussi Bandhs, as the locals call them, are high-rise structures on the two banks of river Sutlej to stop river water from coming over the banks in case of a water surge. These elevated structures are 4.60 to 7.60 meters wide and are also utilised for plying vehicles. It is said that these dams began to be constructed in the early 1960s and their construction was done in various stages. A large part of the Dhussi dam in Punjab is kuchha, but roads have been constructed over them in certain places. ${ }^{4}$ As many as 18 breaches were detected on the banks of Sutlej river in the affected area. Many of the breaches could not be estimated because of the rising water level of the river. It was also observed that Sutlej had changed its course and had affected both livestock and health in many areas. ${ }^{5}$

According to a study conducted by Weiwei Du et al., the health impacts can be divided into immediate, mid-term and long-term effects. The immediate health effects cause maximum mortality by drowning, hypothermia, injuries, and animal bites. There are a few mid-term impacts like sepsis, communicable diseases, poisoning, poor mental health, complications of injury, and starvation. These mid-term impacts can be classified as indirect effects of flooding. Poor mental health, disability, and malnutrition including anaemia can be termed and classified under the long-term impacts of flooding. , $^{6}$

Owing to the seriousness of the health impact of flooding and the inability of the population in the area around river Sutlej, which has the least access to a health facility, this interventional research became of utmost importance.

\section{Aims and Objectives}

- To assess the health impact of floods in District Ludhiana

- To render health care services to flood victims along with health education

\section{Material and Method}

This is a type of cross-sectional interventional project which was initiated in the areas surrounding river Sutlej and covered a population of 4243 of all age groups.

This project was initiated by MKDPCH Hambran, a unit of CMC\&H Ludhiana, under the guidance and supervision of Dr Dhruvendra Lal, the Chief Medical Officer and Assistant Professor in the Department of Community Medicine.

The areas were chalked out on a map by us with the help of the District Epidemiologist and the Civil Surgeon, Ludhiana. Research clearance was taken from the Civil Surgeon Office Ludhiana and ethical waiver was given as the research did not involve any such intervention. The worst-hit areas along the Sutlej river bank which included 07 villages were selected (Khera Bhet, New Razapur, Bhorewaal, Bhurj Lambra, Bhurj Manpur, Aloowaal, and Bhorewaal Judid) (Figures 1 and 2).

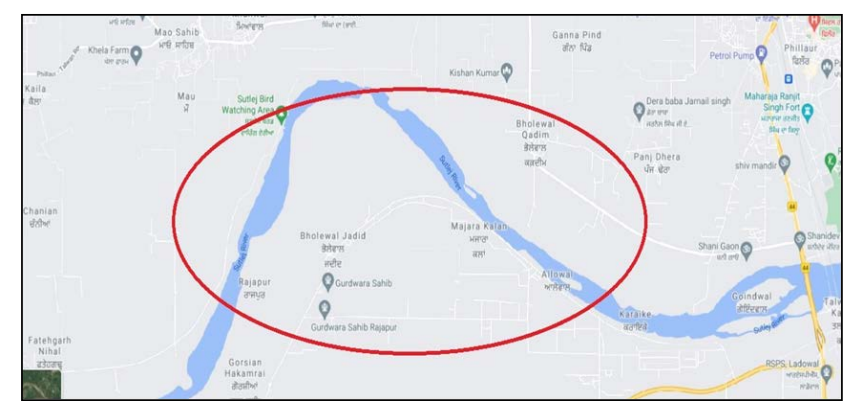

Figure I.Map showing Areas Covered during this Project $^{8}$

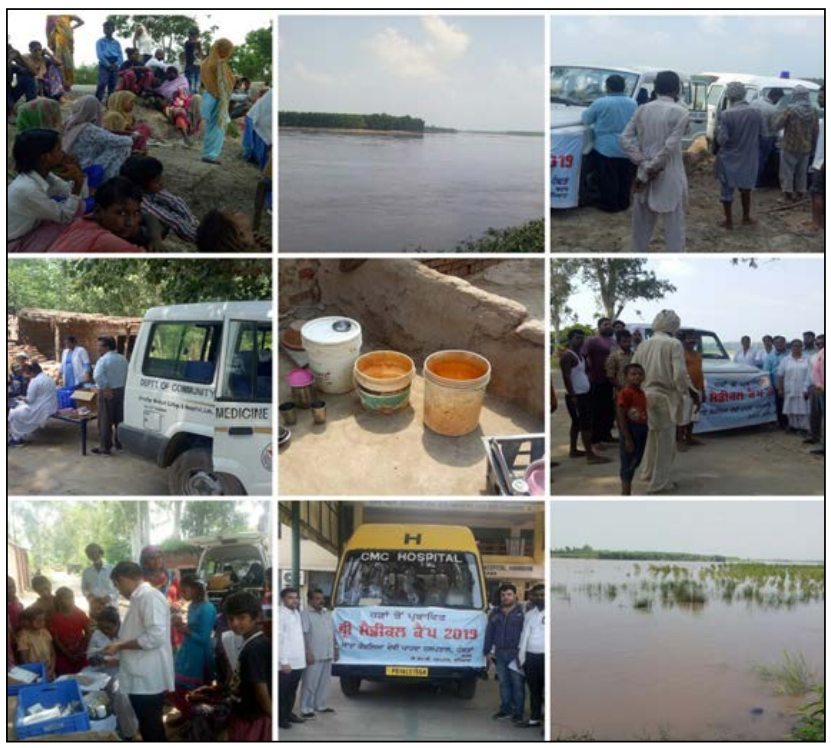

Figure 2.Screening, Intervention by Health Workers

All people living in these villages were interviewed as per the post-emergency syndromic disease surveillance format of $\mathrm{WHO}^{9}$ and free health check-ups and medicines were provided. Apart from this, health education was also 
provided through posters and announcements. Chlorination for drinking water and kerosene oil spray on stranded waters was also advocated.

- Duration: 23rd August 2019 to 03rd September 2019

- Total number of days: 12

- Team: 01 supervisor, 02 doctors, 02 female health workers, 01 male health worker, 01 pharmacist, 01 helper/ attendant

- Total population covered: 4,243

\section{Results}

A total of 4243 people were surveyed from 07 villages around river Sutlej. The distribution of the population according to gender and age is shown in Table 1.

Table I.Distribution of the Population as per Gender and Age

\begin{tabular}{|c|c|}
\hline Variables & N (\%) \\
\hline \multicolumn{2}{|c|}{ Gender } \\
\hline Male & $2307(54.3)$ \\
\hline Female & $1936(45.7)$ \\
\hline Age \\
\hline Under 5 years & $445(10.5)$ \\
\hline Over 5 years & $3798(89.5)$ \\
\hline
\end{tabular}

It was found that 1421 (33.5\%) people were impacted, out of which 546 i.e. $38.4 \%$ of impacted, required medical or surgical intervention, whereas $61.6 \%$ required only counselling. This can be seen in Figure 3.

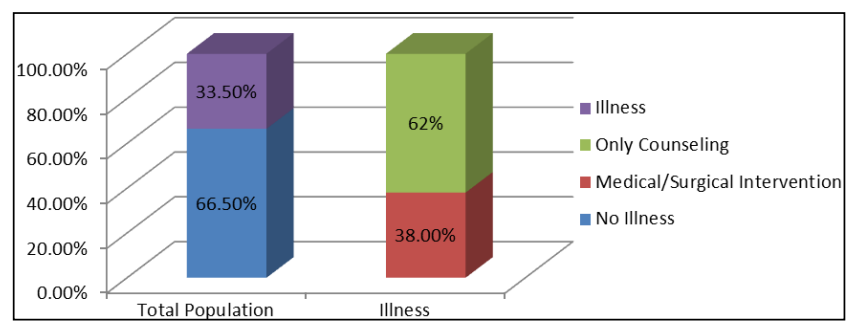

Figure 3. Health Impact on the Population

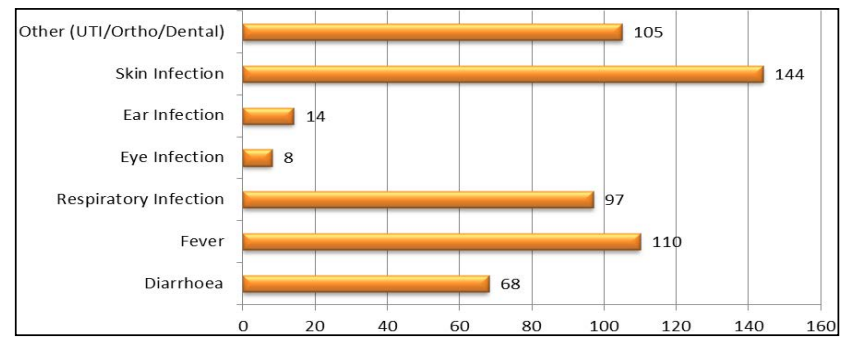

Figure 4.Distribution of Illness among 546 People

It was observed that skin infection was the most common ailment among these people followed by generalised fever, respiratory infection, and diarrhoea (Figure 4).

It was observed that fever was the most common impact followed by skin infections and diarrhoea among children who were less than 5 years of age (Figure 5 ). On the other hand, skin infection was common among people more than 5 years of age followed by fever and acute respiratory infections (Figure 6).

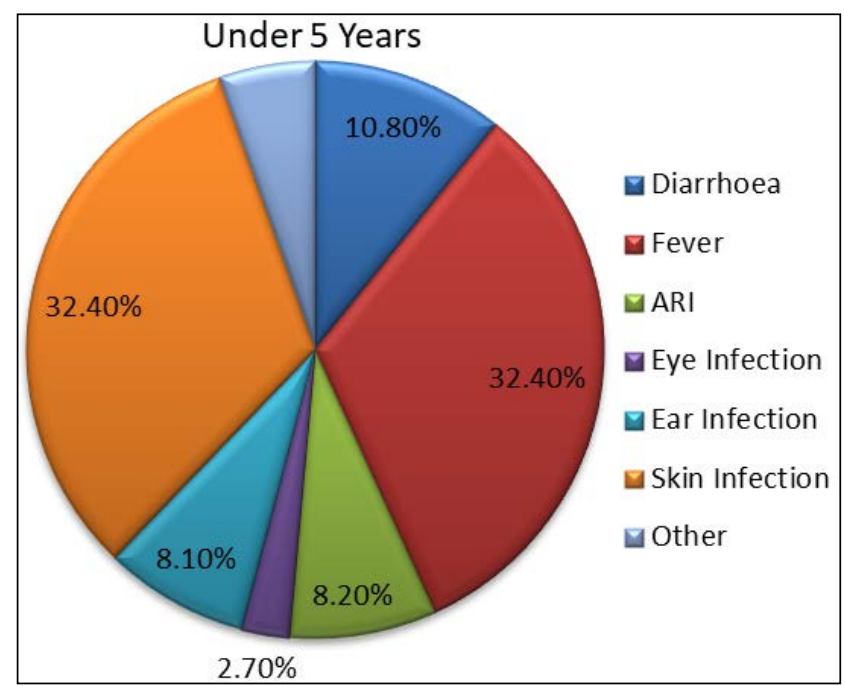

Figure 5.Distribution of Illness among Children Less than 5 Years Old

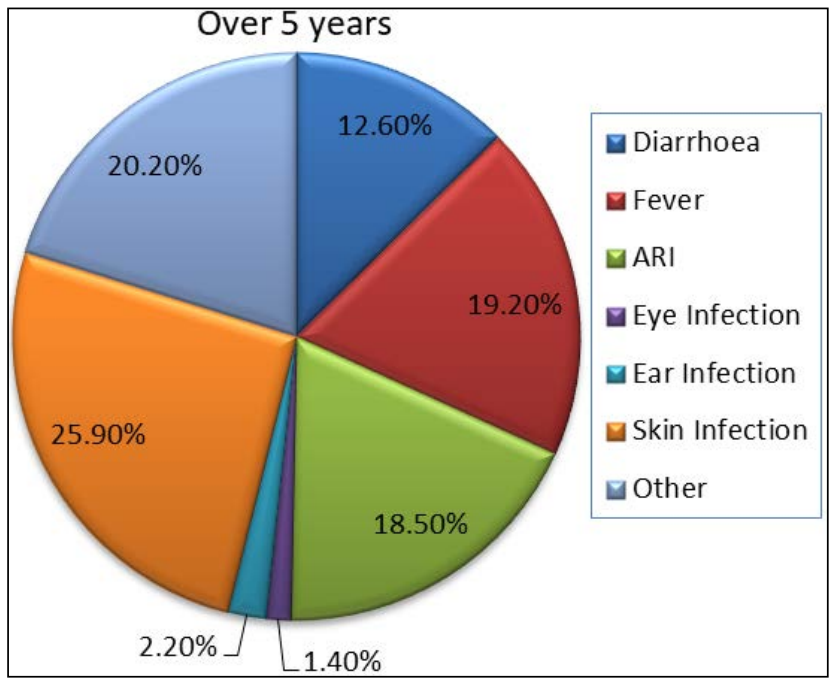

Figure 6.Distribution of Illness among Children More than 5 Years Old

As part of the relief, chlorine tablets (more than 2000) for chlorination of water, antibiotics, antipyretics, de-worming, skin ointment, eye and ear drops were provided to the affected community. People were also provided with mosquito repellant creams and sprays apart from health education. People were educated regarding nutrition, sanitation, waste disposal, and proper handling and storage of food and water.

\section{Discussion}

The project covered seven villages in District Ludhiana which were devastated during the 2019 Sutlej floods, in discussion 
with the Civil Surgeon Office. A total of 4243 population was covered out of which 1421 i.e. 33.5\% needed some kind of intervention. A study published by Lee J et al., showed that 2.9 billion people got affected by water disasters in Asia from 2001 to $2018 .{ }^{10}$ Most of the cases in both groups (under 5 years and over 5 years) belonged to skin diseases, which was in agreement with many studies conducted in rural sectors. ${ }^{5}$ ARI was more prevalent amongst the over 5 years age group while FUO more among the under 5 age group. The cases were divided according to post emergency syndromic disease surveillance format issued by WHO. ${ }^{4}$

The study stressed on the use of early warning systems which will help people living in the low lying areas of rivers like Sutlej to be warned well in advance regarding the impending danger and give them enough time to evacuate. Regular cleaning of Buddha Nalah should be done as it was seen that its backflow caused more damage to the livestock in these areas and such strategies would not only help reduce water overflow in the main river but also aid in reducing water-borne diseases. Spraying of mineral oils like kerosene should be initiated immediately to prevent vector-borne diseases. Desilting of dams should be done on regular basis. More health care awareness and methods of prevention for vector-borne diseases should be provided. Economic aid from the government should be provided as floods create enormous pressure as well as financial load on the common people. This might have an adverse impact on their health-seeking behaviour and health expenditure and more people who are living in poverty would seek medical care when needed. Stress should be given on various methods of disaster mitigation like raising of homes in flood-prone areas, disaster mitigation public awareness programmes, flood plain mapping using software like GIS, adoption and enforcement of land use and zoning practices.

\section{Conclusion}

$33.5 \%$ of the population was impacted. Our focus should be on disaster preparedness. Under 5 children were most commonly affected by fever and skin infections. Respiratory infections, fever, diarrhoea and skin infection were the most common ailments suffered by the people. Most of the people (62\%) who had the disaster impact needed just counselling. Only $38 \%$ required medical or surgical interventions. Special signals like fog horns or other warning systems should be used and people should be made aware of such signals.

\section{Source of Funding: None \\ Conflict of Interest: None}

\section{References}

1. Park K. Park's Textbook of preventive and social medicine. $23^{\text {rd }}$ ed. Jabalpur: Banarsidas Bhanot Publishers. 2015; 795.
2. World Health Organization [Internet]. Flooding and communicable diseases fact sheet; [cited 2019 Sep 17]. Available from: https://www.who.int/hac/ techguidance/ems/flood_cds/en/

3. India Today [Internet]. Light rains in North India, release of water from Bhakra dam curtailed on flood-hit Punjab's request; 2019 [cited 2019 Sep 17]. Available from: https://www.indiatoday.in/india/ story/rains-north-india-bhakra-dam-water-floodpunjab-1591886-2019-08-26

4. The Indian Express [Internet]. Explained: Why rain fury is not the only culprit behind Punjab floods; 2019 [cited 2019 Sep 17]. Available from: https://indianexpress. com/article/explained/why-rain-fury-is-not-the-onlyculprit-behind-punjab-floods5950008/

5. The Indian Express [Internet]. 10 new Dhussi Bandh breaches detected; 2021 [cited 2021 Aug 25]. Available from: https://indianexpress.com/article/india/10-newdhussi-bandh-breaches-detected-5926773/

6. Bich TH, Quang LN, Ha LT, Hanh TT, Guha-Sapir D. Impacts of flood on health: epidemiologic evidence from Hanoi, Vietnam. Glob Health Action. 2011;4:6356. [PubMed] [Google Scholar]

7. Du W, Fitzgerald GJ, Clark M, Hou XY. Health impacts of floods. Prehosp Disaster Med. 2010;25(3):265-72. [PubMed] [Google Scholar]

8. Google.com [Internet]. Google Maps; 2021 [cited 2021 Aug 25]. Available from: https://www.google.com/ maps/@31.0050964,75.7345705,14z

9. World Health Organization [Internet]. WHO Recommended Surveillance Standards. Second edition; 2021 [cited 2021 Aug 25]. Available from: https:// www.who.int/csr/resources/publications/surveillance/ whocdscsrisr992.pdf

10. Lee J, Perera D, Glickman T, Taing L. Water-related disasters and their health impacts: a global review. Progress Disaster Sci. 2020;8:100123. [Google Scholar] 